\title{
Os novos livros do PROSAB
}

Durante o Congresso da ABES em Recife, no dia 23 de setembro deste ano, o Programa de Pesquisa em Saneamento Básico (PROSAB) lançou seis novos livros.

O PROSAB, gerido pela Financiadora de Estudos e Projetos (FINEP), teve como objetivo o desenvolvimento e aperfeiçoamento de tecnologias nas áreas de águas de abastecimento, águas residuárias, resíduos sólidos, lodo e biossólidos, manejo de águas pluviais urbanas e uso racional de água e energia.

De acordo com o Diretório de Grupos de Pesquisa do Sistema Lattes, do CNPq, a maioria dos grupos de pesquisa que desenvolvem pesquisas em saneamento básico no Brasil cadastrados participam do PROSAB. Na última década, dos trabalhos apresentados nos Congressos da ABES, os trabalhos desenvolvidos no PROSAB têm se destacado notoriamente tanto em quantidade quanto em relação aos prêmios recebidos.

O PROSAB configurou-se como o maior programa de pesquisa em saneamento básico do país, e também o principal esteio do desenvolvimento tecnológico neste setor nos últimos dez anos. Como as linhas de pesquisa e os temas pesquisados foram sempre definidos por um Grupo Coordenador, composto por representantes dos órgãos de fomento à pesquisa e outros órgãos do governo, do principal banco financiador do setor, das empresas prestadoras de serviço, das universidades e centros de pesquisas, e da associação brasileira de engenharia sanitária e ambiental, através de consulta à comunidade científica e também aos potenciais usuários dos resultados das pesquisas, delimitam um universo representativo das demandas e das tendências em ciência e tecnologia do saneamento básico e, enfim, do desenvolvimento tecnológico no Brasil.

Atua através de editais públicos, com linhas de pesquisa previamente definidas, que selecionam projetos de pesquisa consonantes com as linhas preestabelecidas para constituírem redes cooperativas de pesquisa de âmbito nacional.
Desde 1996, quando teve início uma nova fase, lançou cinco editais, financiados pela FINEP, pelo CNPq e pela Caixa Econômica Federal, contando com diferentes fontes de recursos, inclusive CTHidro. O mais recente, o Edital 5, teve início em 2006 e foi concluído efetivamente em 2009, resultando nos seis novos livros.

Ao final de cada edital, são lançados livros referentes aos temas pesquisados, mas que não se limitam aos resultados das pesquisas e promovem uma verdadeira revisão e atualização do conhecimento. Ao todo, no período de 1999 a 2009, já foram lançados 33 livros, todos disponíveis para consulta e cópia ("download" em produtos) gratuita no site da FINEP.

Enorme patrimônio legado do PROSAB são esses livros, que publicam não somente o conhecimento desenvolvido nas pesquisas em saneamento básico no âmbito do Programa, mas também o conhecimento dos pesquisadores reunidos e articulados nas redes cooperativas de pesquisa. Como o PROSAB reúne em torno de cada tema os principais estudiosos e pesquisadores do Brasil em cada edital, com poucas exceções, pode-se dizer que os seus livros registram o conhecimento brasileiro recente sobre saneamento básico.

Os novos livros foram elaborados pelos pesquisadores das seis redes temáticas de pesquisa do último edital do PROSAB (Edital 5), das quais participaram 45 grupos de pesquisa de 27 distintas instituições de todas as regiões do Brasil.

Ao todo, os autores dos seis livros são 185, mas como alguns autores participaram de mais de um livro, na verdade foram 179 profissionais, estudiosos e pesquisadores do domínio da engenharia sanitária e ambiental, entre eles os mais renomados do país, que redigiram os novos livros do PROSAB. É um número respeitável de autores, capaz realmente de realizar uma completa e competente atualização do conhecimento.

Os livros publicados em 2009 pelo PROSAB, e seus conteúdos, são os seguintes:

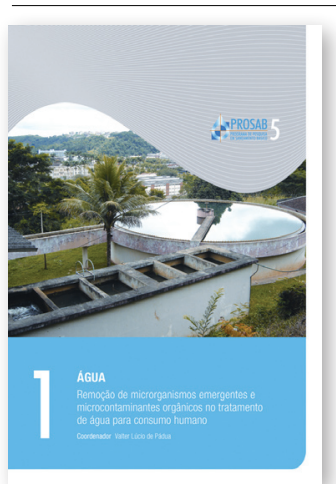

\section{Livro 1}

Remoção de micro-organismos emergentes e microcontaminantes orgânicos no tratamento de água para consumo humano. Valter Lúcio de Pádua (coordenador) e outros (25 autores). Rio de Janeiro: ABES, 2009. 392p. (ISBN: 978-85-7022-165-0)

O conteúdo está desenvolvido em nove capítulos: 1. Tratamento de água para consumo humano: panorama mundial e ações do PROSAB - Edital 5, Tema 1; 2. Contaminantes orgânicos presentes em microquantidades em mananciais de água para abastecimento público; 3. Microrganismos emergentes: protozoários e cianobactérias; 4. Tratamento de água e remoção de protozoários; 5. Tratamento de água e remoção de cianobactérias e cianotoxinas; 6 Remoção e transformação de agrotóxicos; 7. Desreguladores endócrinos; 8. Remoção de gosto e odor em processos de tratamento de água; 9 . Análise de risco aplicada ao abastecimento de água para consumo humano. Contém, ainda, um apêndice sobre as Metodologias Utilizadas na Quantificação de Microcontaminantes por Cromatografia.

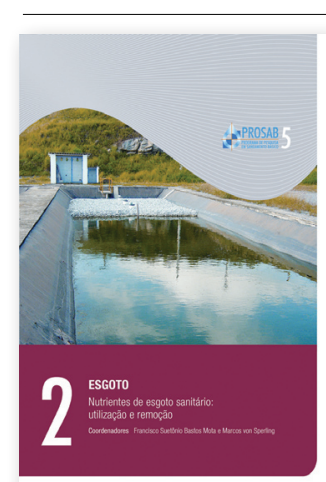

\section{Livro 2}

Nutrientes de esgoto sanitário: utilização e remoção. Francisco Suetônio Bastos Mota e Marcos von Sperling (coordenadores) e outros (29 autores). Rio de Janeiro: ABES, 2009. 428p. (ISBN: 978-85-7022-164-3)

Contém os seguintes capítulos: 1. Introdução; 2. Impacto dos nutrientes do esgoto lançado em corpos de água 3. Utilização de esgoto tratado na agricultura: aporte de água e nutrientes; 4. Utilização de nutriente de esgoto tratado em hidroponia; 5. Utilização de nutrientes de esgoto tratado na piscicultura; 6. Remoção biológica de nitrogênio: aplicações para o sistema de lodo ativado; 7. Remoção biológica de fósforo no sistema de lodo ativado: mecanismos e configurações; 8 . Nitrificação em reatores aeróbios com biomassa aderida; 9 . Remoção de nutrientes em sistemas naturais; 10. Remoção de nutrientes por processos físico-químicos; 11. Síntese global do desempenho e da confiabilidade dos sistemas de tratamento de esgoto; 12. Elementos para decisão acerca do reúso ou lançamento do esgoto tratado. 


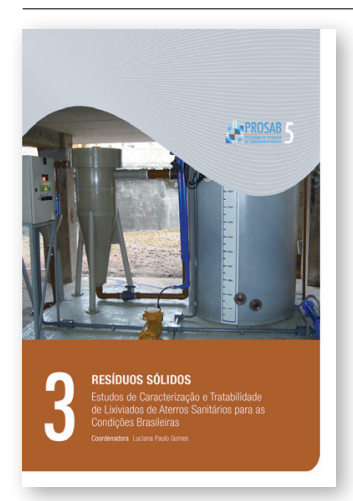

Livro 3

Estudos de caracterização e tratabilidade de lixiviados de aterros sanitários para as condições brasileiras. Luciana Paulo Gomes (coordenadora) e outros (51 autores). Rio de Janeiro: ABES, 2009. 360p. (ISBN: 978-85-7022-163-6)

Contendo o seguintes capítulos: 1. Introdução; 2. Geração e características do lixiviado; 3. Estudo do processo de stripping de amônia de lixiviado de aterro sanitário; 4. Tratamento físico-químico de lixiviados: estudos em escala de bancada com precipitação química, coagulação/floculação, adsorção com carvão ativado e reagente de fenton; 5. Tratamento de lixiviados de aterro sanitário em sistema de lagoas; 6 . Aplicação de tratamentos biológicos anaeróbios para lixiviados de RSU; 7. Tratamento biológico aeróbio com remoção de nitrogênio em sistemas de lodos ativados; 8. Tratamento combinado de lixiviados de aterros de resíduos sólidos urbanos com esgoto sanitário; 9. Tratamentos não-convencionais: estudos iniciais em barreiras, banhados e camadas de cobertura superficial; 10. Tratamento de lixiviados por evaporação.

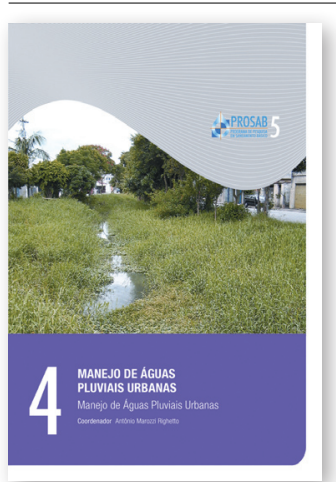

\section{Livro 4}

Manejo de águas pluviais urbanas. Antônio Marozzi Righetto (coordenador) e outros (36 autores). Rio de Janeiro: ABES, 2009. 396p. (ISBN: 978-85-7022-162-9)

Conteúdo: 1. Manejo de águas pluviais urbanas; 2. Monitoramento em drenagem urbana; 3. Modelos computacionais para drenagem urbana; 4. Técnicas compensatórias em águas pluviais; 5. Resíduos sólidos na drenagem pluvial urbana; 6. Estudo quali-quatitativo e de manejo de águas pluviais em área de drenagem piloto na cidade de Natal-RN; 7. Microrreservatório de detenção em logradouro público; 8. Estudos de caso em avaliação quali-quantitativa dos resíduos sólidos na drenagem urbana; 9. Qualidade da água em reservatórios de contenção de cheias urbanas; 10. Avaliação de fluxo de poluentes em tempo seco e durante eventos de chuva em uma microbacia urbanizada no município de Belo Horizonte; 11 - Experimentos com trincheira de infiltração e vala de detenção; 12 Avaliação da percepção pública do risco de enchentes e de medidas de controle de inundações em áreas urbanas.

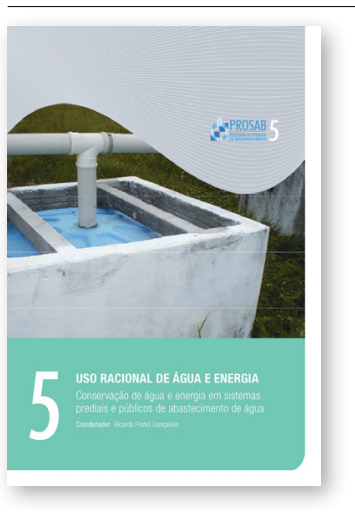

\section{Livro 5}

Conservação de água e energia em sistemas prediais e públicos de abastecimento de água. Ricardo Franci Gonçalves (coordenador) e outros (18 autores). Rio de Janeiro: ABES, 2009. 352p. (ISBN: 978-85-7022-161-2)

Todo o conteúdo divido em seis capítulos: 1. Introdução; 2. Consumo de água; 3. Consumo de energia; 4. Tecnologias de conservação em sistemas públicos; 5. Tecnologias de conservação em sistemas prediais; 6. Perspectivas futuras: água, energia e nutrientes.

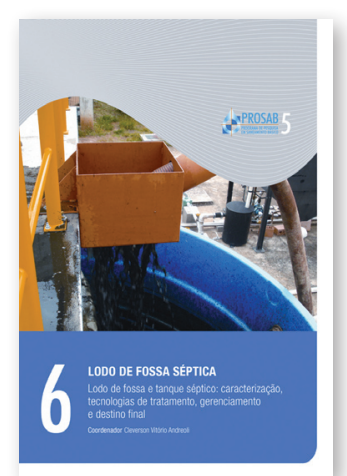

\section{Livro 6}

Lodo de fossa e tanque séptico: caracterização, tecnologias de tratamento, gerenciamento e destino final. Cleverson Vitório Andreoli (coordenador) e outros (26 autores). Rio de Janeiro: ABES, 2009. 388p. (ISBN: 978-85-7022-166-7)

Conteúdo nos capítulos: 1. Introdução; 2. Definições, histórico e estimativas de geração de lodo séptico no Brasil; 3. Caracterização física, química e microbiológica do lodo de fossa séptica; 4. Tratamento de lodo de fossa/ tanque séptico; 5. Tratamento combinado de lodo de tanque séptico e de fossas com esgoto sanitário; 6. Gestão do lodo de fossa séptica; 7 . Avaliação multiobjetivo e multicritério de alternativas de gestão de lodo de fossa - tanque/ séptico; 8. Lodo de fossas sépticas - uma análise crítica.

São todos excelentes livros. Costumo dizer que os livros do PROSAB, em seu conjunto, constituem o que há de melhor na bibliografia brasileira sobre saneamento básico. Podem ser adquiridos impressos na ABES, e também já estão disponíveis para "download" gratuito no endereço habitual (www.finep.gov.br/prosab/index.html).

A diretoria da FINEP decidiu não lançar edital para o PROSAB em 2009. O edital lançado para a área de habitação e saneamento, que se propõe a dar continuidade às ações do PROSAB, não contempla vários dos aspectos fundamentais do Programa que garantiram seu enorme sucesso.

Por ocasião do último Congresso da ABES, com cerca de 5 mil participantes, foram apresentadas pelos congressistas e aprovadas em plenário diversas moções manifestando preocupação quanto à continuidade do PROSAB e favoráveis à sua manutenção.

A ABES, representando 10 mil associados, levou recentemente um documento oficial à FINEP para manifestar a preocupação do setor de saneamento com as mudanças de critérios e a falta de definição de alguns procedimentos fundamentais no edital para pesquisa em saneamento e habitação que parece se distanciar bastante do processo exitoso do PROSAB.

São muitas as preocupações. No novo edital, foi extinto o Grupo Coordenador, de papel vital para o sucesso do PROSAB. No edital de 2009, também não está explicitado como serão as reuniões de acompanhamento e avaliação, fundamentais no modelo de gestão desenvolvido 
no programa. Também não é previsto o acompanhamento constante de consultores ad hoc (consultores permanentes e próprios de cada rede), que sempre estiveram presentes nas reuniões com todos os coordenadores de projeto das redes de pesquisa, e representantes do Grupo Coordenador.

Algumas perguntas permanecem sem respostas. Quais são realmente as vantagens de fundir dois programas que apresentaram separadamente resultados tão expressivos? Por que suprimir marcas tão consolidadas e nomes tão fortes no país e até no exterior, como PROSAB e HABITARE?

O maior risco é, certamente, a perda dos mais importantes aspectos que caracterizaram o PROSAB: o entrosamento entre os pesquisadores das instituições participantes por meio de reuniões presenciais trimestrais de avaliação, troca de informações e efetiva cooperação; o acompanhamento constante de consultores proativos e do Grupo Coordenador, norteador vigilante e presente; a disponibilidade dos resultados do avanço do conhecimento de forma acessível ao engenheiro e ao estudante mais comuns.

E sobre os livros, tão importantes, que já são aguardados ansiosamente e que sempre resultaram de condição explicitada em cada edital? O edital de 2009 não faz referência ao compromisso de divulgação dos trabalhos desenvolvidos através da publicação de livros. Não se sabe se essas publicações continuarão sendo apoiadas, incentivadas e exigidas.

Mas certamente a comunidade científica, os pesquisadores e os profissionais da área da engenharia sanitária e ambiental do Brasil não vão permitir a extinção do PROSAB, e outros livros que foquem temas mais atuais do setor com tamanha qualidade e abrangência ainda haverão de ser editados.

\section{Comentário elaborado pelo Coordenador da Coluna Livros, Professor Cícero Onofre de Andrade Neto Natal (RN), Brasil, 2 de dezembro de 2009}

A sessão "Livros", que a cada edição traz resumos comentados sobre livros de interesse na área, tem como principal objetivo permitir que o leitor, de forma rápida, se atualize e conheça o que há disponível no mercado editorial. As contribuições deverão ser encaminhadas para: resa@abes-dn.org.br 